\title{
Território, territorialidade e fronteira: o problema dos limites municipais e seus desdobramentos em Belém/PA
}

\author{
Territory, territoriality and border: the problem of municipal limits and its \\ unfolding in Belém - PA
}

Marlon Lima da Silva ${ }^{[0]}$, Helena Lúcia Zagury Tourinho ${ }^{[b]}$

[a] Universidade Federal do Pará (UFPA), Faculdade de Geografia e Cartografia, Belém, PA, Brasil

[b] Universidade da Amazônia (UNAMA), Programa de Pós-Graduação em Desenvolvimento e Meio Ambiente Urbano, Belém, PA, Brasil

\section{Resumo}

0 trabalho versa sobre o problema dos limites municipais à luz dos conceitos de território, territorialidade e fronteira. Mostra-se que imprecisões e inadequações nas leis, no que se refere ao estabelecimento dos limites fronteiriços de Belém, no Estado do Pará, com outros municípios, têm resultado em conflitos de mapas, de gestão pública, além da divisão de ocupações/conjuntos habitacionais, causando uma série de problemas aos gestores municipais e, principalmente, aos moradores das áreas em conflito. Ao analisar estudos realizados pelos poderes públicos com o objetivo de redefinir os limites, revela-se que tais pesquisas são incompletas e falham por não considerarem aspectos relativos às territorialidades dos grupos envolvidos na questão. Partindo-se do princípio que a definição de limites territoriais é muito mais do que uma questão de técnica de cartografia, embora esta seja importante, defende-se que a proposição de novos limites municipais deve considerar os conceitos de território, territorialidade e fronteira, além de ser apresentada a metodologia desenvolvida pelos autores deste artigo, que são técnicos da Companhia de Desenvolvimento e Administração da Área Metropolitana de Belém.

Palavras-chave: Território. Territorialidade. Fronteira. Limite municipal de Belém.

\section{Abstract}

This paper discusses the problem of city limits of Belém to the concepts of territory and territoriality border. It shows that inaccuracies and inadequacies in the laws establishing the border limits of Belém with other cities have resulted in conflicts of maps, public management, beyond the division of occupations/housing, causing several problems to cities managers, and especially to residents of conflicting areas. By analyzing studies conducted by public authorities with the aim of redefining the limits, we reveal that such studies are incomplete and fail not to consider aspects concerning territoriality of the groups involved in the issue. Assuming that the definition of boundaries is much more than a matter of mapping technique, although this is

MLS é mestre em Geografia (UFPA); professor substituto (UFPA), e-mail: marlon.angelim@yahoo.com.br HLZT é doutora em Desenvolvimento Urbano (UFPE); professora e pesquisadora (UNAMA), e-mail: helenazt@uol.com.br 
important, argues that the proposition of new municipal limits should consider the concepts of territory and territoriality and border present the methodology developed by the paper's authors whom are technicians of the City Development Company of Belém.

Keywords: Territory. Territoriality. Borders. City limits of Belém.

\section{Introdução}

Os limites geodésicos atuais de Belém, no Estado do Pará, foram oficializados por uma série de leis estaduais estabelecidas nas décadas de 1940,1950 e 1990. Trata-se de uma linha extensa que separa oito municípios, traçada quando ainda não se dispunha de recursos precisos de demarcação cartográfica. Naquele contexto, além de dificuldades de identificação dos marcos naturais (nome e configuração exatos das ilhas, corpos d'água e áreas verdes), não havia contiguidade nas malhas viárias na linha fronteiriça belenense, já que a implantação induzida pelo poder público de conjuntos habitacionais e as ocupações "espontâneas" populares nas periferias urbanas eram feitas, em grande parte, configurando uma estrutura "em árvore", ou seja, conectadas a grandes e poucos eixos rodoviários e entremeadas por vazios urbanos.

Como resultado, vários tipos de conflitos territoriais relativos aos limites municipais são verificados, causando uma série de problemas aos gestores municipais e, principalmente, aos habitantes que moram e àqueles que têm seus negócios na área, suscitando questões de ordem técnica, política e administrativa sobre as áreas limítrofes.

Esse cenário tem motivado a realização de estudos pelo poder público estadual e municipal com a finalidade de repensar os limites municipais e propor novas linhas fronteiriças. Em 2012, o Instituto de Desenvolvimento Econômico, Social e Ambiental do Pará (IDESP) elaborou um estudo sobre limites municipais no Estado do Pará e propôs a redefinição dos limites entre Belém e Ananindeua, sem consultar as prefeituras e as populações envolvidas. Em 2014, a Prefeitura Municipal de Belém (PMB) começou a desenvolver estudos específicos sobre suas áreas fronteiriças que apresentavam divergências de limites territoriais. De fato, a questão dos limites municipais é um problema que precisa ser enfrentado.

0 presente artigo retrata a intenção de técnicos da PMB em discutir alguns dos problemas já identificados, assim como as reflexões que vêm sendo realizadas com vistas a construir uma proposta de revisão dos limites municipais de Belém. Parte-se do princípio de que a definição de limites territoriais é muito mais do que uma questão de técnica de cartografia, embora esta seja importante. Considera-se que se trata, sobretudo, de uma questão social, envolvendo elementos políticos, econômicos e culturais. Nesse debate, entende-se que os conceitos de território, territorialidade e fronteira merecem ser considerados em destaque.

O trabalho está estruturado em três partes: inicialmente, são discutidas as bases conceituais que subsidiarão o entendimento da problemática dos limites municipais de Belém; no segundo momento, são apontados os problemas já identificados nas fronteiras desse município; por fim, são indicadas algumas diretrizes a serem consideradas no processo de formulação da proposta de revisão dos limites municipais.

\section{Limites, território e territorialidade}

A fronteira não é apenas uma linha mapeada cartograficamente e descrita em seus marcos geodésicos com a finalidade de separar duas ou mais unidades espaciais. Se assim o fosse, os problemas relativos aos limites territoriais se restringiriam à tecnologia empregada para proceder referido traçado e descrição. Quando se mencionam os termos "limite territorial" ou "fronteira", é necessário remeter-se às noções mais amplas de "território" e de "territorialidade".

0 conceito de território vincula-se à categoria poder, porém não apenas ao poder no sentido concreto de dominação (poder político), mas também ao poder simbólico, ligado à apropriação de determinados grupos para com seu espaço de vivência (Haesbaert, 2004).

Sendo o espaço delimitado por e a partir de relações de poder, o território não se refere somente aos limites político-administrativos estabelecidos por linhas ou marcos divisórios (Souza, 2003). Sua abrangência é múltipla, envolvendo diferentes espaços e agentes 
sociais, indo desde a ação do Estado delimitando as fronteiras de um país, por exemplo, até a definição da abrangência espacial das organizações comunitárias de bairros, de conjuntos habitacionais, de ocupações etc.

De fato, todos, de certa forma, exercem controle sobre parcelas do espaço, constituindo territórios, seja no sentido mais político do termo, seja na perspectiva simbólica. É da necessidade de controle sobre o território que emergem as noções de fronteiras, manifestando-se como a expressão espacial do uso político do território (Cataia, 2008).

A fronteira possui duas visões científicas bem definidas: "[...] trata da história política entre Estados nacionais e do limite de soberania de um poder central e [...] trata do vivido e das interações entre populações em zonas fronteiriças" (Ferrari, 2014, p. 23).

0 debate histórico sobre as fronteiras reflete a abrangência do conceito. O Quadro 1 lista as principais contribuições científicas para a construção do entendimento do termo fronteira.

Ao analisar esse quadro, nota-se que grande parcela das definições do conceito de fronteira relaciona-se com a concepção do território como uma instância político-administrativa formal, ou seja, sob controle do Estado. Essa concepção, embora ainda dominante, vem sendo acompanhada de outras formas de se conceber a fronteira e o território, que envolvem visões mais amplas, incluindo aquelas não hegemônicas e que se contrapõem ao próprio Estado.

Essas reflexões são fundamentais para se pensar a problemática dos limites municipais de Belém, visto que, alertam para a necessidade de superar a visão tradicional e avançar no sentido de considerar também as múltiplas relações de poder que são estabelecidas no espaço. Para isso, deve-se trilhar uma análise integrada dos territórios, vinculando-os à ideia de territorialidade, isto é, "[...] a tentativa de um indivíduo ou grupo para afetar, influenciar ou controlar pessoas, fenômenos e relações, e para delimitar e impor controle sobre uma área geográfica" (Sack, 1986, p. 19).

Segundo Raffestin (1993, p. 158), "[...] a territorialidade reflete a multidimensionalidade do vivido territorial pelos membros de uma coletividade, pelas sociedades em geral". Desse modo:

[...] a territorialidade, além de incorporar uma dimensão mais estritamente política, diz respeito também às relações econômicas e culturais, pois está intimamente ligada ao modo como as pessoas utilizam a terra, como elas próprias se organizam no espaço e como elas dão significado ao lugar (Haesbaert, 2004, p. 3).

De fato, quando são estabelecidos limites entre determinadas áreas (municípios, Estados, nações etc.),

\section{Quadro 1 - Principais autores e contribuições sobre o conceito de fronteira}

\begin{tabular}{|c|c|}
\hline Autor & Ideias sobre o conceito de "fronteira" \\
\hline Friedrich Ratzel & $\begin{array}{l}\text { As fronteiras são o órgão periférico do Estado, destacando-se duas características: fronteira como zona - as cidades - e fronteira como linha - traçado } \\
\text { geodésico. Linhas e zonas são limites. }\end{array}$ \\
\hline Rudolf Kjellén & As fronteiras são a epiderme dos Estados. \\
\hline Jacques Ancel & As fronteiras são isóbaras políticas, ou seja, linhas permanentes de tensão entre dois campos de força. \\
\hline Jean Gottmann & $\begin{array}{l}\text { Afirma que o mundo não é uma "bola de bilhar", sem fronteiras, porque o território é o "abrigo de um povo", por isso a importância das fronteiras } \\
\text { delimitando regimes políticos distintos. }\end{array}$ \\
\hline Everardo Backheuser & $\begin{array}{l}\text { Tomando as ideias de Ancel e de Backheuser, elabora uma "equação de pressão de fronteira" (Supan já havia proposto uma fórmula parecida), por } \\
\text { considerar a fronteira como construção geopolítica dos Estados. }\end{array}$ \\
\hline Karl Haushofer & $\begin{array}{l}\text { A fronteira é a região da expansão. Um povo deve adquirir o "sentido" da fronteira, "esse precioso fator espiritual que mantém a vida". A fronteira } \\
\text { não corresponderia à linha geométrica do direito internacional. }\end{array}$ \\
\hline Hildebert Isnard & As fronteiras são a cristalização dos limites da organização do espaço realizado por distintos projetos políticos, inclusive projetos não estatais. \\
\hline Michel Foucher & $\begin{array}{l}\text { "A fronteira é uma descontinuidade geopolítica, com funções de delimitação real, simbólica e imaginária". Considera as fronteiras segundo díades, } \\
\text { bem como a existência de fronteiras internas. }\end{array}$ \\
\hline Claude Raffestin & $\begin{array}{l}\text { A fronteira é zona camuflada em linha. As divisões político-administrativas são encaradas também como fronteiras (fronteiras internas), porque elas } \\
\text { seriam a armadura de sustentação e de vitalidade da fronteira externa. Zonas e linhas fariam parte de um sistema de limites. }\end{array}$ \\
\hline
\end{tabular}

Fonte: Cataia $(2008$, p. 16). 
são relações de poder que estão sendo delimitadas espacialmente, indicando, em tese, até onde vai o controle territorial efetivo de um determinado grupo, povo ou nação. Porém, dentro desse espaço delimitado, diversas relações de poder podem configurar a presença de outras territorialidades, tornando mais complexa a ideia de fronteira e também de território.

Conforme Saquet (2009, p. 87), “[...] a territorialidade efetiva-se em distintas escalas espaciais e varia no tempo através das relações de poder, das redes de circulação e comunicação, da dominação, das identidades".

Ocorre que, em uma sociedade organizada territorialmente em países, Estados e municípios, mesmo levando-se em conta as múltiplas territorialidades presentes nos espaços geográficos, há que se demarcar limites fixos, claramente descritos e representados em termos cartográficos por meio de linhas divisórias.

Cataia (2008), baseado em Ratzel $(1987,1988)$, classifica as fronteiras em três tipos - políticas, naturais e artificiais (Quadro 2) -, fornecendo subsídios para se refletir sobre a tipologia da fronteira do município de Belém e sobre parte dos aspectos que devem ser considerados ao propor a alteração de sua linha divisória.

Como se percebe, as tipologias apresentadas tratam de uma concepção rígida de fronteira, ligada unicamente ao território enquanto ente político-administrativo do Estado. De fato, apesar da análise fechada do território e da fronteira, essas tipologias ajudam a compreender como tem sido tradicionalmente realizada a demarcação de linhas divisórias entre países, Estados e municípios.

O caso mais notório de demarcação de fronteiras talvez tenha sido registrado na chamada "Partilha da África”, durante a Conferência de Berlim (1884-1885). Na ocasião, as potências coloniais negociaram a divisão territorial do continente africano, traçando novos limites fronteiriços de modo arbitrário, desconsiderando o território e a territorialidade dos diferentes grupos tribais lá presentes. Como resultado dessa divisão, grupos tribais aliados foram separados e tribos rivais foram unidas, suscitando uma série de conflitos que até hoje são caracterizados como a denominação geral de "problema das fronteiras artificiais".

Ressalte-se que, como mostra Cataia (2008, p. 8), limites político-administrativos estaduais e municipais, ou seja, as fronteiras internas de um país ou unidade da federação, também expressam projetos políticos diferenciados.

Os projetos políticos hegemônicos não são hegemônicos na totalidade de um território nacional, há oposições, por isso são construídas fronteiras internas. As fragmentações se dão dessa maneira. Portanto, existem fronteiras internas a partir de projetos que são distintos. Os movimentos separatistas baseiam-se nessa

Quadro 2 - Tipologias de fronteiras segundo Friedrich Ratzel

\begin{tabular}{|c|c|c|}
\hline Tipos & Subtipos & Atribułos \\
\hline \multirow{6}{*}{ Políticas } & Simples & Aquela que não tem contato com outra área política. \\
\hline & Dupla & Demarca duas zonas de contato (por exemplo, de dois territórios nacionais). \\
\hline & Fechada & São enclaves dentro de uma área política (por exemplo, País Basco). \\
\hline & Descontínua & São exclaves, isto é, partes de Estados que estão fora de seus domínios territoriais (por exemplo, as llhas Malvinas). \\
\hline & Deficiente & $\begin{array}{l}\text { Onde ocorrem conflitos por novas demarcações fronteiriças. Estes indicariam a(s) deficiência(s) da(s) demarcação(ões) } \\
\text { anterior(es). }\end{array}$ \\
\hline & Elástica & $\begin{array}{l}\text { Por falta de boas cartas ou por erros cartográficos, muitas fronteiras aumentam ou diminuem suas extensões. } 0 \text { desenvolvimento } \\
\text { técnico aprimorado diminui os "erros". }\end{array}$ \\
\hline \multirow{3}{*}{ Naturais } & Marcos físicos & $\begin{array}{l}\text { Os limites do ecúmeno são montanhas, rios, lagos, desertos, florestas, costas etc. Os atributos naturais das fronteiras não } \\
\text { concernem só ao solo; o povo é aí incluído quando ele constitui um limite étnico. }\end{array}$ \\
\hline & Boas & Quando a fronteira se presta, fisicamente, à proteção do Estado em um momento de guerra. \\
\hline & Más & Quando a fronteira física não se presta à defesa militar de um Estado. \\
\hline Artificiais & Demarcadas & Qualquer fronteira demarcada por tratado, mesmo que apoiada sobre um marco físico. \\
\hline
\end{tabular}

Fonte: Cataia $(2008$, p. 12). 
construção territorial, mas não têm o monopólio das fraturas, pois os regionalismos e localismos também compartilham rupturas territoriais. Esse é um movimento histórico, por isso as fronteiras são históricas e não naturais (Cataia, 2008, p. 8).

Embora municípios possuam, necessariamente, fronteiras políticas/artificiais - considerando ou não as múltiplas territorialidades de seus agentes -, historicamente a demarcação desses limites tem sido realizada, em grande medida, com base em marcos físicos como corpos d'água, florestas, montanhas etc. Eixos viários, limites de propriedades públicas e privadas constituem também marcos importantes considerados na definição de limites territoriais.

Na Amazônia, definir a fronteira, baseada em marcos naturais, já é uma tarefa difícil por si só, em virtude da imensidão da floresta, presença de inúmeros rios, furos, igarapés e ilhas de diferentes tamanhos, além das descontinuidades existentes da ocupação humana. Nesse contexto, considerar questões mais amplas relativas ao poder e às territorialidades é mais um desafio que se adiciona a outros ainda não superados, como será visto a seguir.

\section{Limites territoriais de Belém e seus problemas}

O município de Belém está localizado na região Norte do Brasil, constituindo-se na capital do Estado do Pará. Seus limites territoriais foram estabelecidos pelas Leis Estaduais no 158/1948 (Pará, 1948), no 1.127/1955 (Pará, 1955) e no 5.778/1993 (Pará, 1993). A primeira definiu a totalidade dos limites, os quais, em 1955, foram modificados pela segunda lei, e a última redefiniu a fronteira continental com o município de Ananindeua. Ressalte-se que, com todos os demais municípios limítrofes (Santo Antônio do Tauá, Santa Bárbara do Pará, Marituba, Acará, Barcarena, Ponta de Pedras e Cachoeira do Arari), as fronteiras são insulares.

O traçado pelo Instituto Brasileiro de Geografia e Estatística (IBGE) com base nas leis estaduais mencionadas, a Figura 1 apresenta a linha fronteiriça do município de Belém e indica a localização dos municípios limítrofes.

Três grupos de problemas atuais nesses limites podem ser apontados, cada um com repercussões nos demais. 0 primeiro refere-se às divergências entre os mapas de limites municipais utilizados nas diferentes esferas de poder. 0 segundo diz respeito às questões administrativas, referentes à provisão, à abrangência espacial do atendimento e à gestão de equipamentos públicos municipais na faixa da fronteira. Por fim, o terceiro grupo decorre do processo de urbanização propriamente dito, ou seja, retrata o que ocorre quando um vazio urbano é ocupado, tornando inadequada a linha de fronteira traçada artificialmente, sem marcos físicos claros à visão humana comum. Tais conflitos serão detalhados a seguir, com base nas definições de território, territorialidade e fronteira.

\section{Os conflitos "das leis" e "dos mapas"}

A Figura 2 apresenta sobrepostas duas bases cartográficas com os limites territoriais de Belém. Trata-se dos limites estabelecidos nas Leis Municipais no 7.682/1994 (Belém, 1994) e no 7.806/1996 (Belém, 1996), utilizados pela PMB, e nas leis estaduais, usados pelo IBGE para a coleta do censo de 2010. Como se pode constatar, no extremo sul de Belém, a chamada Ilha do Cintra, ou do Maracujá, foi adicionada a Belém nas leis municipais.

Ao analisar esse mapa, nota-se também que os limites sobre as águas não coincidem. Enquanto o mapa apresentado pelo IBGE divide, praticamente ao meio, os corpos d'água situados entre os municípios limítrofes a Belém. No limite estabelecido em documentos da PMB a demarcação apresenta um traçado bem mais reduzido e irregular sobre os corpos d'água.

A Lei Estadual no 1.127/1955 (Pará, 1955) delimita, dentre outras coisas, a fronteira na porção sul de Belém, limite com o município de Acará. Na referida lei, consta que a Ilha do Cintra pertence de fato ao Acará, fazendo referência que o limite contornaria o chamado Furo do Benedito, ficando para Belém as demais ilhas ao norte, por exemplo, a Ilha Grande. Assim, o limite utilizado pelo IBGE estaria de acordo com a lei estadual, contrastando com a base cartográfica usada pela PMB.

A questão central que emerge nesse cenário é a seguinte: quais os fatores que motivaram a utilização de um limite diferente pela PMB? Na realidade, a PMB não vem respeitando a legislação estadual. Em vez disso, utiliza como referência as Leis Municipais no 7.682/1994 e no 7.806/1996, que estabeleceram os distritos administrativos e os bairros de Belém, 


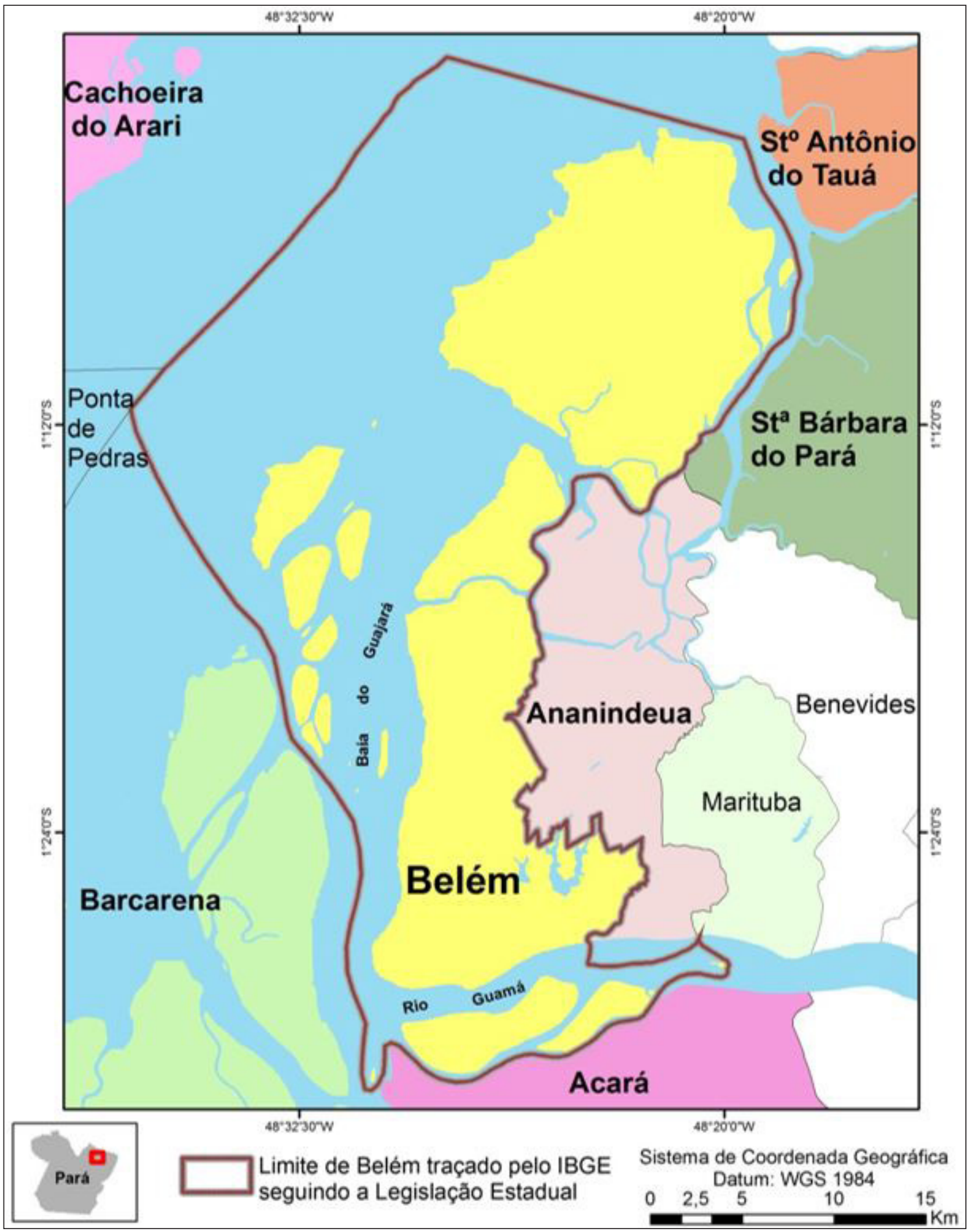

Figura 1 - Municípios que fazem fronteira com Belém, Estado do Pará

Fonte: Elaborado pelos autores com base no Instituto Brasileiro de Geografia e Estatística (IBGE, 2010). 


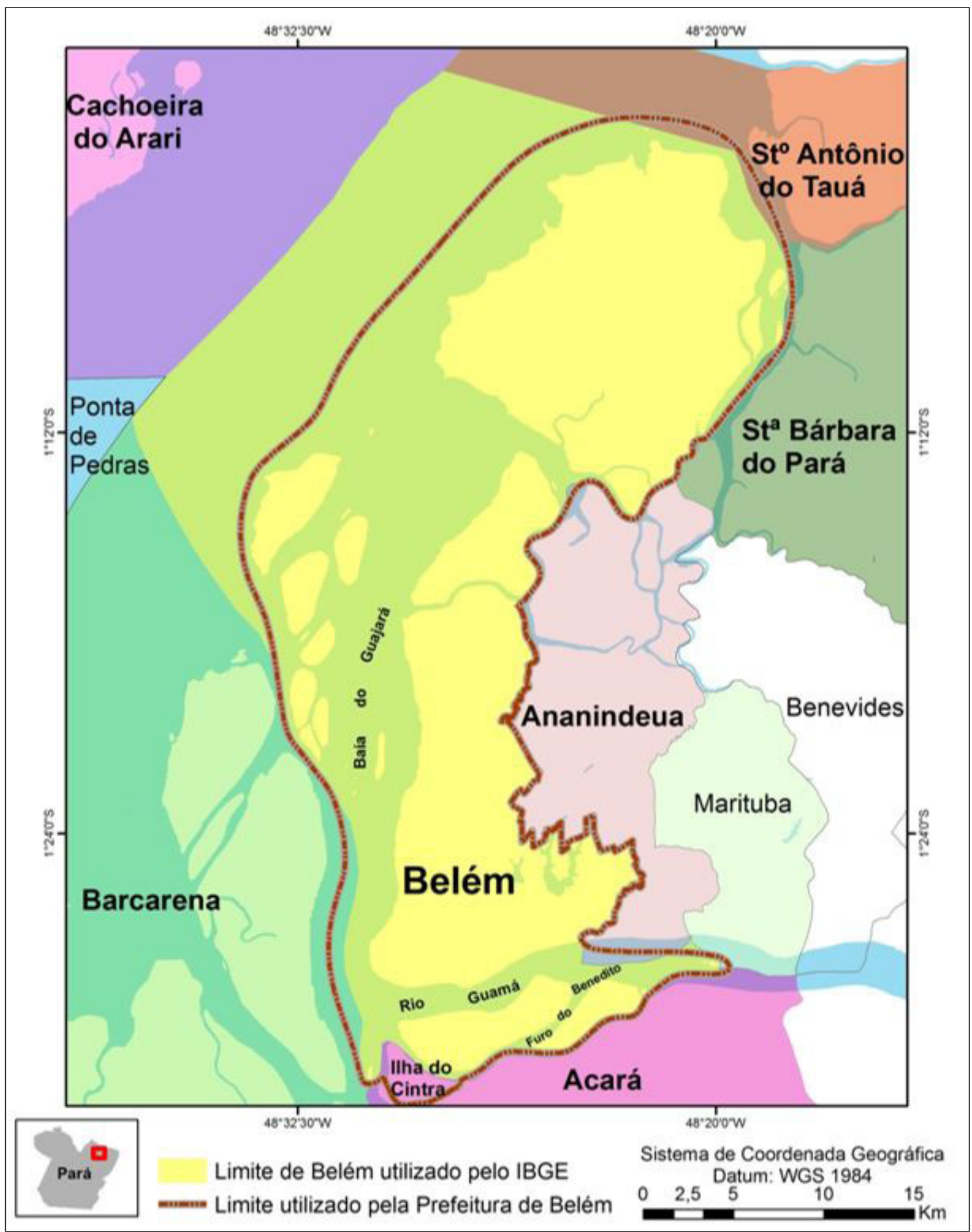

Figura 2 - Limites territoriais de Belém, Estado do Pará, usados pela Prefeitura Municipal de Belém (PMB) e pelo Instituto Brasileiro de Geografia e Estatística (IBGE)

Fonte: Elaborado pelos autores com base no Instituto Brasileiro de Geografia e Estatística (IBGE, 2010). 
respectivamente. E por que essas leis não consideram as leis estaduais de datas precedentes?

Em busca de respostas, foram entrevistados dois técnicos da Companhia de Desenvolvimento e Administração da Área Metropolitana de Belém (CODEM) que participaram da elaboração dos estudos que resultaram na lei de delimitação dos bairros e distritos de Belém. Eles informaram que, na época, a prefeitura não dispunha dos recursos tecnológicos avançados, como computadores e equipamentos de Global Positioning System (GPS), muito menos de imagens de satélites, o que dificultava o conhecimento do território.

A questão da Ilha do Cintra revelou parcialmente essas dificuldades. De acordo com os técnicos entrevistados, não se sabia o real percurso do Furo do Benedito, citado na Lei Estadual no 1.127/1955. A população residente nas proximidades o posicionava de modo que a Ilha do Cintra ficava no território de Belém, e não no de Acará. Daí o motivo pelo qual, segundo os entrevistados, a equipe da PMB incorporou a referida ilha ao seu território, tornando seu mapa divergente do aprovado pela lei estadual. Trata-se, claramente, de uma questão que envolve diferentes territorialidades, notadamente dos municípios de Belém e Acará e da população residente na ilha.

Além disso, acrescenta-se também a territorialidade do governo federal, considerando que os corpos d'água são geridos pela União, e não pelos municípios. Vale lembrar que os limites sobre as águas não são precisos nas leis estaduais e municipais, visto que as coordenadas estão ausentes nas leis que os estabeleceram, fazendo menção somente às fronteiras com o nome dos rios, furos e baías. Diante disso, o IBGE utiliza um padrão no qual os corpos d'água são divididos simetricamente entre os municípios, o que contrasta com a base cartográfica utilizada pela PMB. Neste caso, os limites sobre as águas utilizados pela PMB diferem de toda a base usada do IBGE, gerando uma série de problemas.

Pensar a redefinição desses limites requer, portanto, considerar essas territorialidades como ponto de partida. De fato, há diferentes percepções sobre o território. Mesmo considerando o Furo do Benedito como um marco físico de extrema relevância na demarcação desse limite, pois se caracteriza como uma fronteira natural, a indefinição e a ausência de acordo sobre o seu real percurso já representa, por si só, a complexidade da questão. Evidencia que definir limites não constitui simplesmente uma tarefa de ordem técnico-cartográfica. Além disso, ressalta-se que, apesar de algumas fronteiras serem caracterizadas como naturais, "[...] a escolha de um marco é sempre uma escolha política, ainda que o marco físico continue sendo um rio ou uma montanha" (Cataia, 2008, p. 13).

Daí decorre que o levantamento e a apresentação de todas as sobreposições conflitantes entre os referidos limites, à luz do conceito de território e territorialidade, consiste no primeiro e importante passo para se pensar mais detalhadamente as ações no sentido de se propor novos limites, considerando os diferentes interesses envolvidos.

A seguir será analisado o segundo grupo de conflitos, evidenciando o problema relacionado à localização contraditória de equipamento público em Belém, mas administrado pelo município de Acará.

\section{Os "conflitos da gestão pública"}

Outro aspecto relevante envolvido na questão dos limites territoriais diz respeito à responsabilidade de provisão e gestão de equipamentos públicos, bem como ao raio de abrangência espacial da prestação de serviços e da cobrança de tributos. É comum as populações que vivem em faixas fronteiriças reclamarem por receber cobranças de tributos de duas prefeituras e por ter suas demandas por serviços recusadas em escolas e postos de saúde, sob a alegação de o equipamento pertencer a um município e suas residências estarem localizadas no município adjacente. Esses problemas, novamente, revelam conflitos de territorialidades.

Exemplo desse tipo de conflito se encontra na Ilha do Murutucu, ou Murutura, localizada no município de Belém (Figura 3). Ali, no território de Belém, a Prefeitura do Acará mantém a Escola de Ensino Fundamental ACAIMU para atender à população acaraense. Com base nesse argumento, solicitou-se à $\mathrm{PMB}$ que verificasse a possibilidade de revisão dos limites territoriais entre os dois municípios.

Diferentemente da questão anterior, em que não se sabia ao certo o real traçado fronteiriço, neste caso não há dúvida de que a referida ilha pertence, de fato, ao município de Belém - que mantém, inclusive, uma série de outros equipamentos públicos. Segundo um levantamento preliminar realizado 


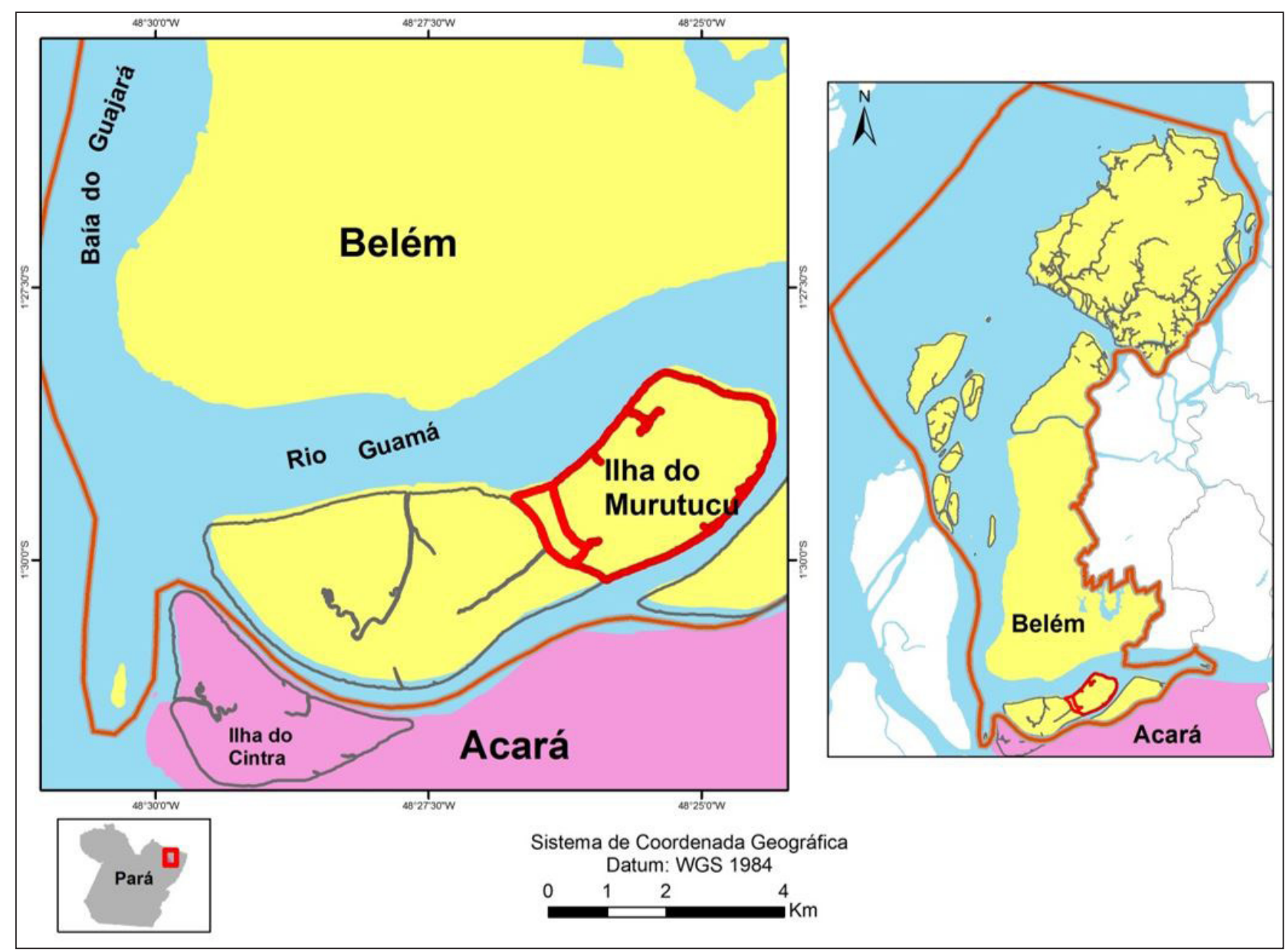

Figura 3 - Mapa de localização da llha do Murutucu, ou Murutura, Estado do Pará Fonte: Elaborado pelos autores com base no Instituto Brasileiro de Geografia e Estatística (IBGE, 2010).

pela CODEM, existem dez equipamentos urbanos da PMB localizados nas ilhas do extremo sul, dentre eles: anexos escolares, centro comunitário, casa da família etc.

Mais uma vez, o território e a territorialidade se apresentam como conceitos importantes nesse debate, considerando que há sobreposição de territorialidades entre os municípios.

\section{Os conflitos "das ocupações"}

A ocupação de vazios urbanos, com assentamentos habitacionais cujos traçados e territorialidades não coincidem com os limites artificiais anteriormente estabelecidos, tem gerado vários conflitos, como os existentes entre os municípios de Belém e Ananindeua na ocupação conhecida por Olga Benário.
A delimitação fronteiriça atual que separa os municípios de Belém e Ananindeua foi definida na Lei Estadual no 5.778/1993¹ (Pará, 1993). Na maior parte da descrição da lei, os marcos utilizados para a definição da fronteira não revelam dúvida quanto ao real traçado divisor. Tal precisão se deve em função do uso de marcos consistentes, por exemplo, eixos viários e corpos d'água (furos, nascentes etc.), constituindo limites rígidos pelos quais seguem as linhas divisórias. 0 problema desse limite se revela um problema de territorialidade, na porção sudeste de Belém, mais especificamente no bairro Águas Lindas, onde se

\footnotetext{
${ }^{1}$ Esta lei faz referência ao Protocolo de Intenções celebrado entre esses municípios em 1991. No entanto, comparando o memorial descritivo da lei como o memorial presente no Protocolo de Intenções, nota-se a presença de algumas divergências em determinados pontos de coordenadas, apresentando-se aqui mais um conflito "de mapas".
} 
localiza a ocupação Olga Benário. Isso porque, quando a lei foi aprovada, em 1993, nesse trecho da fronteira não havia ruas, casas nem equipamentos públicos $\mathrm{e}$ privados. Na verdade, predominava uma vasta área verde que foi interceptada artificialmente pela linha divisória. A Figura 4 faz o comparativo espaço-temporal e a Figura 5 mostra mais detalhadamente a situação atual.

Após 21 anos da aprovação da referida lei, nota-se que novos usos se impõem no lugar da antiga área verde, atribuindo dinâmica complexa nesse trecho da fronteira. Essa dinâmica se expressa, sobretudo, na proliferação de áreas ocupadas de forma irregular, caracterizando os chamados "assentamentos espontâneos" ou "ocupações". De modo geral, esses espaços constituem alternativas para a população de baixa renda que necessita de moradia, porém não dispõe de renda compatível para a aquisição no mercado formal.

Como se fazem de maneira informal, esses assentamentos não seguem diretrizes urbanísticas nem passam por processos de análise e aprovação por parte dos órgãos que controlam o parcelamento, o uso e a ocupação do solo, o que faz com que só após suas implantações os problemas referentes aos limites se manifestem.
Ressalta-se que, a exemplo do que aconteceu em várias áreas metropolitanas no Brasil, a periferia de Belém também cresceu em direção ao município vizinho (Ananindeua), formando uma vasta área conurbada, contribuindo para a criação de grandes conjuntos habitacionais e, posteriormente, de ocupações irregulares. Com a extinção da política do Banco Nacional de Habitação (BNH) em 1986, esvaziou-se a produção de conjuntos habitacionais populares, motivando ainda mais a proliferação de ocupações no limite com o município de Ananindeua (única fronteira continental).

Foi nesse contexto que, durante a década de 1990, surgiu a ocupação Olga Benário. Esta se encontra dividida entre os municípios de Belém e Ananindeua, de modo que os limites territoriais estabelecidos em 1993, hoje seccionam quadras, lotes e até mesmo edificações de propriedade privada, causam uma série de problemas à gestão municipal e, sobretudo, aos moradores que não sabem a que município recorrer para a solução dos problemas infraestruturais lá presentes.

Tendo em vista a resolução dos problemas fronteiriços existentes nos limites de vários municípios do Estado, o IDESP realizou, em 2012, um estudo intitulado "Projeto de Revisão dos Limites Municipais", no qual identificou como problemas entre os municípios de Belém e Ananindeua a separação da ocupação Olga

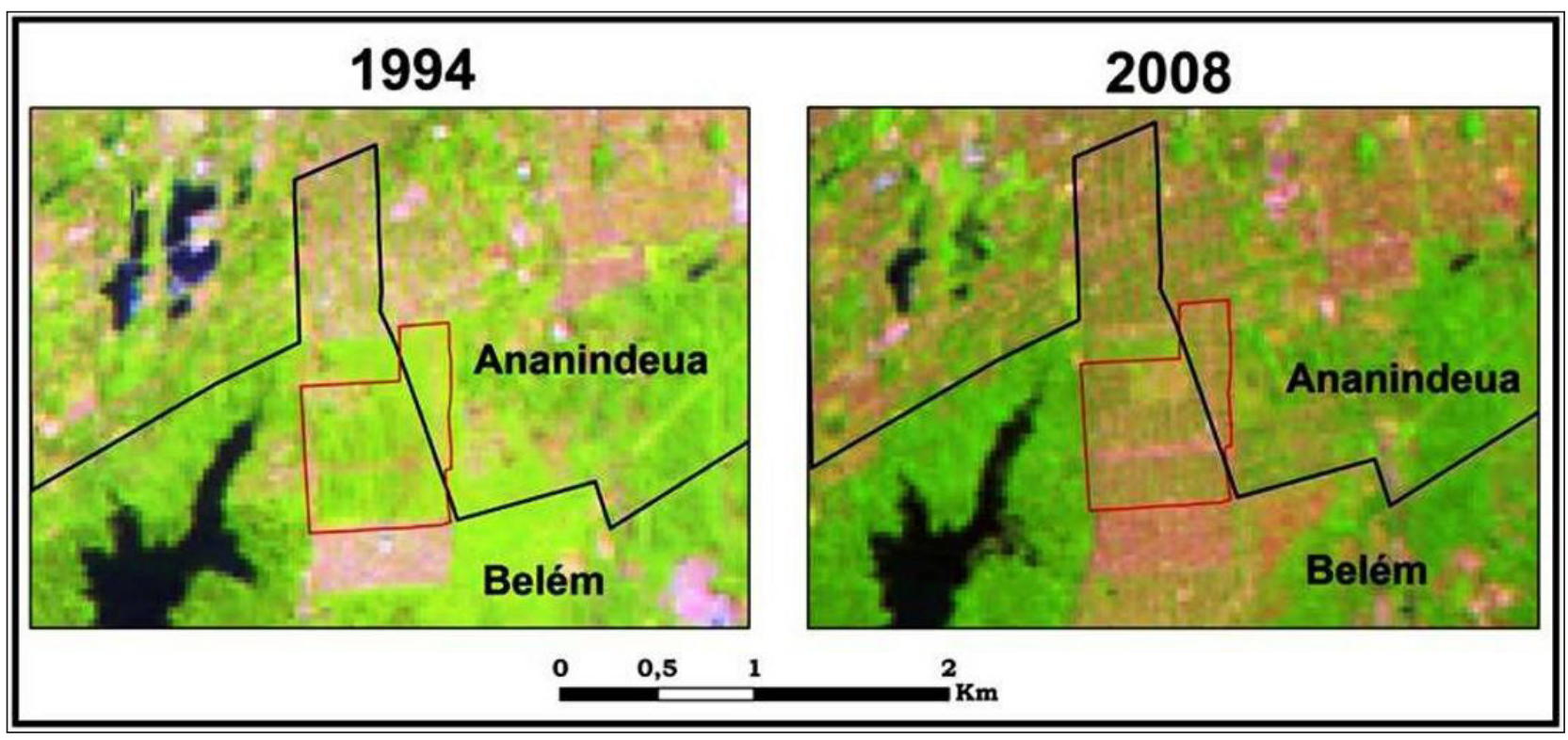

Figura 4 - Comparativo espaço-temporal na ocupação Olga Benário, Estado do Pará Fonte: Elaborado pelos autores com base em imagem LANDSAT 5 TM (1994 e 2008) do Instituto Nacional de Pesquisas Espaciais (INPE) e no Instituto Brasileiro de Geografia e Estatística (IBGE). 


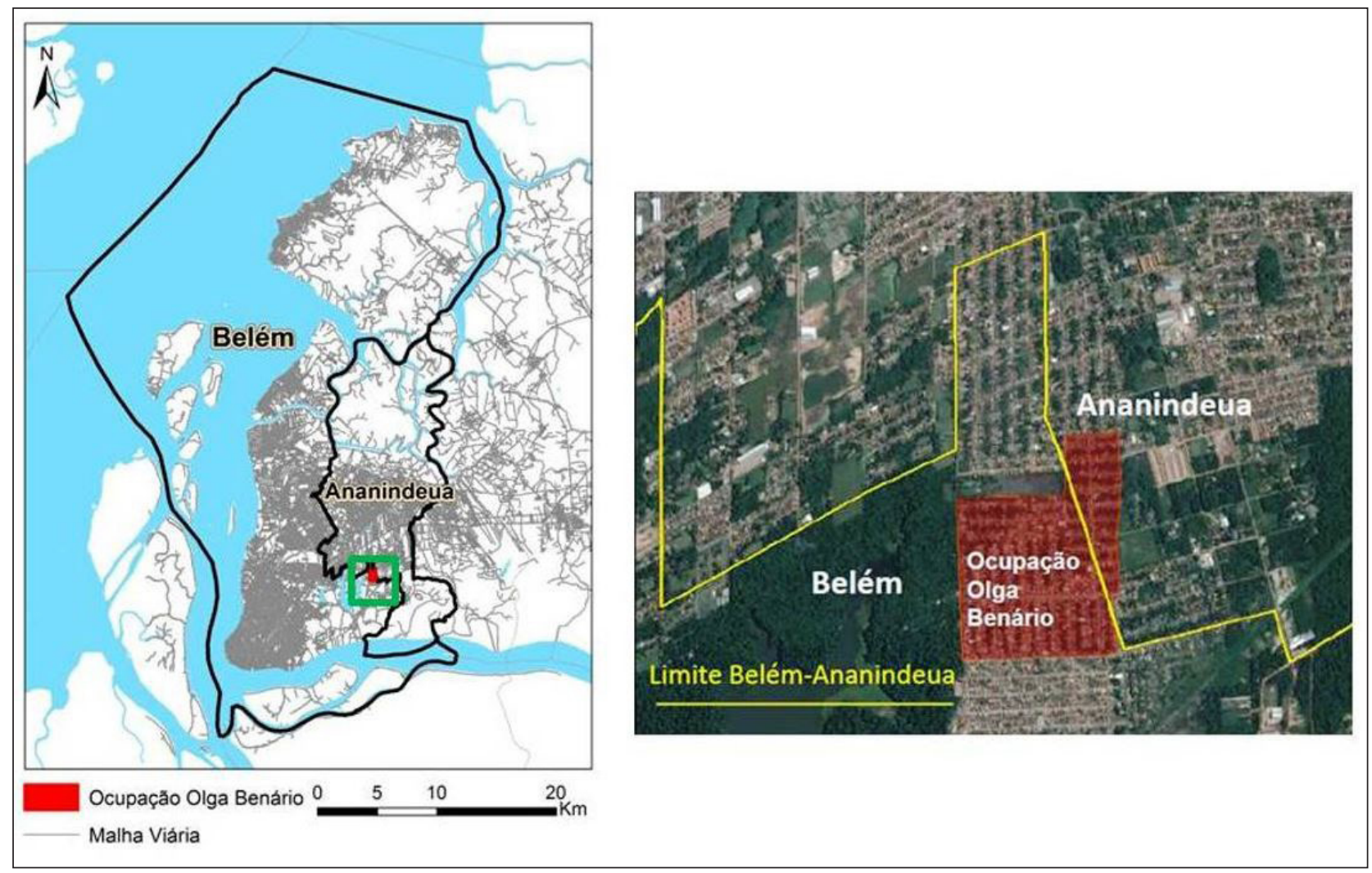

Figura 5 - Localização da ocupação Olga Benário e fronteira de Belém com Ananindeua, Estado do Pará

Fonte: Elaborado pelos autores com base no Instituto Brasileiro de Geografia e Estatística (IBGE, 2010).

Benário e do Parque Estadual do Utinga (PEUT) - este criado em 2011 pelo Decreto no 265 . Para equacioná-los, foi proposta a aplicação de um critério matemático, segundo o qual o município que abrigasse a maior percentagem da área do quarteirão e do Parque os incorporaria ao seu território. Por exemplo, se mais de $50 \%$ de um quarteirão estiver no município "A", ele passará a pertencer integralmente ao município "A" (IDESP, 2012). A Figura 6 apresenta a proposta que resultou da aplicação desse critério.

A proposta do IDESP de redefinição dos limites entre Belém e Ananindeua, ao optar pelo uso exclusivo do critério matemático, desconsiderou uma série de outros aspectos de grande relevância, por exemplo, a relação de pertencimento da população com o município, a origem dos serviços ofertados, os limites das ocupações, o histórico da área etc. Dito de outra maneira, a proposta desenvolvida pelo órgão do Estado simplesmente ignorou completamente, o debate sobre território e territorialidade, debate este fundamental para a compreensão da complexidade presente nas áreas fronteiriças.
Nota-se que a maior parte da área da ocupação Olga Benário encontra-se em Belém. Tal ocupação não deixa de representar uma expressão espacial do poder, no sentido político e simbólico, caracterizando-se, assim, como um território. A representação dos moradores por meio da presença do centro comunitário revela o exercício do poder, ou seja, a territorialidade. De fato, dividir esse território significa impor uma nova territorialidade, rompendo ou fragmentando a antiga. Nesse sentido, moradores, que antes eram atendidos por equipamentos públicos (escolas, creches etc.) comuns aos moradores da ocupação, agora poderão não mais ter acesso a esses serviços com a divisão.

Desse modo, se o ajuste proposto fosse aprovado, a ocupação Olga Benário permaneceria dividida entre Belém e Ananindeua, mantendo-se, de certa forma, a problemática do traçado. É válido realçar, porém, um elemento importante desse estudo, que foi o fato de se ter alertado para o problema da separação entre os dois municípios do PEUT, o qual, até então, não havia sido identificado.

Não se pode ignorar que a delimitação estabelecida pelo IDESP tem seu mérito técnico. A utilização de 


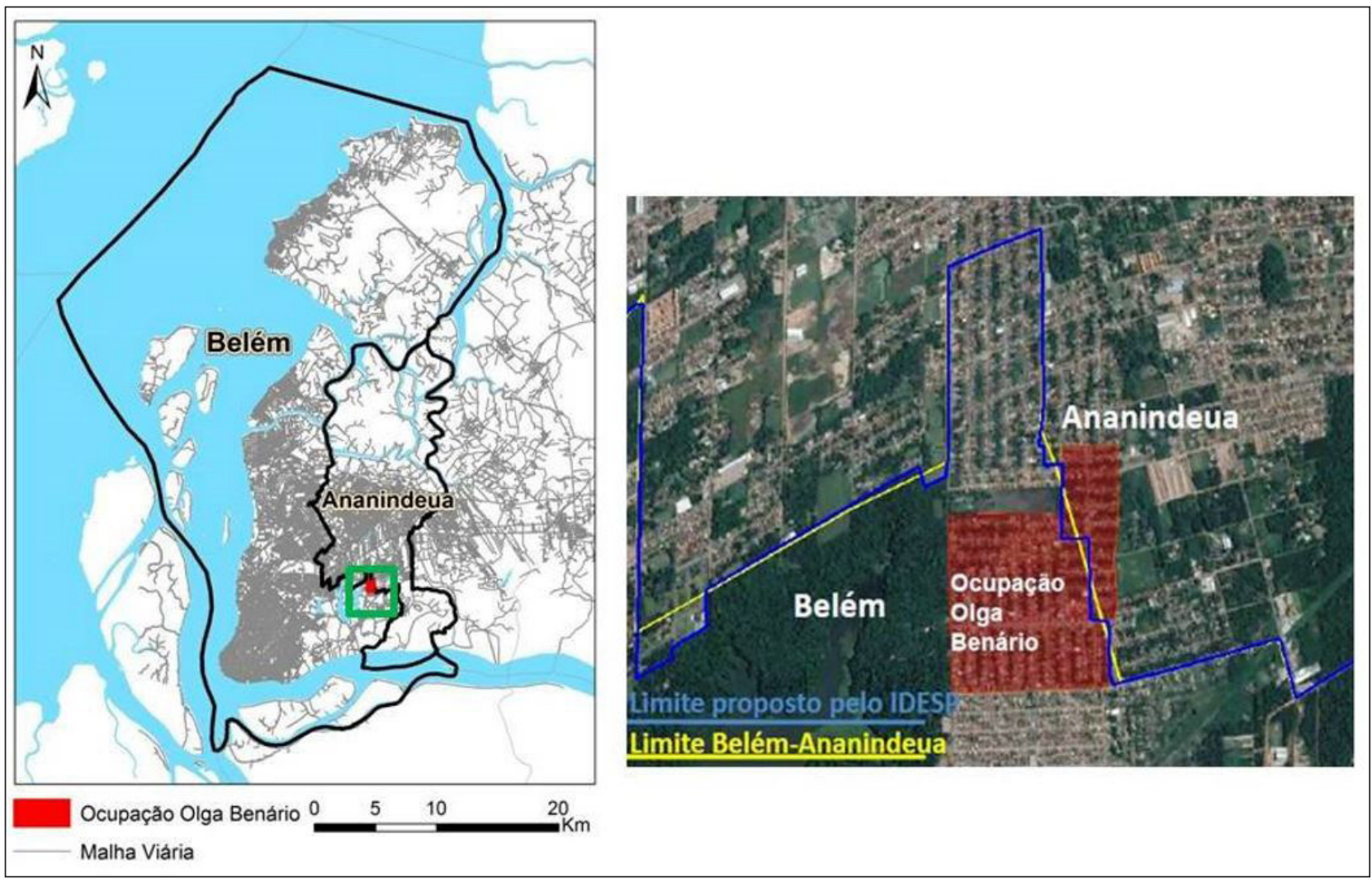

Figura 6 - Proposta do Instituto de Desenvolvimento Econômico, Social e Ambiental do Pará (IDESP) para redefinição dos limites entre Belém e Ananindeua, Estado do Pará

Fonte: Elaborado pelos autores com base no Instituto Brasileiro de Geografia e Estatística (IBGE, 2010).

parâmetro matemático isenta de juízo de valor, e seu resultado não pode simplesmente ser ignorado. No entanto, é necessário se pensar em parâmetros que vão para além dos números, de modo que se incorporem também outros aspectos de natureza política, econômica e social. Afinal, o território não consiste apenas em área que pode ser medida e quantificada. Trata-se, na verdade, de um espaço complexo, repleto de contradições e conflitos que expressam diferentes interesses, ações e objetos.

Diante desse cenário, faz-se indispensável a readequação das áreas limítrofes à luz dos conceitos de território e territorialidade. Esse trecho da fronteira mostra-se atualmente adensado, apresentando aproximadamente 6 mil moradores, conforme dados do IBGE (2010). Essa população carece de infraestrutura e não sabe para qual município recorrer. Portanto, as indefinições nos limites territoriais atingem diretamente a qualidade de vida dos moradores e impossibilitam a gestão territorial pelos órgãos competentes.

\section{A proposta de revisão}

Tendo em vista a resolução de questões semelhantes e de outras, os autores do presente artigo, técnicos da CODEM, elaboraram, em 2014, um "Plano de Trabalho para Redefinição dos Limites Territoriais de Belém”, cujo objetivo é formular uma proposta fundamentada de revisão desses limites. Esse plano de trabalho estabelece como primeira etapa a análise diagnóstica de toda faixa de fronteira municipal, entendendo como faixa o espaço obtido a partir do traçado de 500 metros para cada lado do limite instituído, espaço este ajustável conforme o padrão de ocupação identificado em cada trecho. Nessa fase são identificados os diferentes usos do solo presentes nos diversos trechos de fronteira e demarcadas as "áreas-problema", as quais serão, na segunda etapa, alvos de estudos mais detalhados, no sentido de identificar as territorialidades nelas presentes (Belém, 2014).

Para isso, está prevista a realização de consultas in loco para identificar a identidade e o sentimento 
de pertencimento dos moradores, empreendedores e prestadores de serviços na área, assim como para coletar os principais problemas, anseios e sugestões das pessoas relacionadas aos limites municipais.

Com base nas territorialidades identificadas, serão traçadas, para discutir com a sociedade, alternativas de configuração territorial, apontando as vantagens e desvantagens de cada configuração, inclusive no que tange às questões ligadas aos impactos tributários oriundos das propostas. Afinal, a arrecadação de tributos municipais, assim como o repasse de verbas federais ${ }^{2}$, depende do quantitativo populacional e de atividades que cada município dispõe no seu território. Nesse contexto, perder população ou atividades em virtude de novos limites territoriais significa perder recursos.

Com essas inserções, espera-se lançar mão das noções de território e de territorialidade, e construir uma nova forma de lidar com o problema dos limites territoriais, colocando o homem e suas contradições como eixo relevante no processo de proposição e decisão, sem perder de vista as facilidades e vantagens do uso de marcos físico naturais.

\section{Considerações finais}

Os conceitos de território, territorialidade e fronteira possibilitam a identificação e a análise mais profunda de uma série de problemas referentes aos limites municipais de Belém.

Ao serem transpostos para o estudo de caso de Belém, notou-se que as questões relacionadas à territorialidade estavam, direta ou indiretamente, presentes em todas as três problemáticas já identificadas como conflitos de limites territoriais na capital paraense.

$\mathrm{Na}$ análise do que foi denominado de "conflito dos mapas" - incompatibilidade dos traçados dos mapas usados pela prefeitura e pelo IBGE -, revelou-se que, para além de meros problemas de traçado cartográfico dos mapas, estavam os interesses divergentes com relação ao posicionamento da Ilha do Cintra, ou do Maracujá, revelando percepções diferenciadas do território.

No estudo do exemplo utilizado para evidenciar o chamado "conflito da gestão", apontou-se o interesse do

\footnotetext{
${ }^{2}$ Como exemplo, tem-se o Fundo de Participação dos Municípios (FPM), que depende do quantitativo populacional.
}

município do Acará em incorporar a Ilha do Murutucu, ou Murutura, hoje inserida no território de Belém.

E, por fim, o exemplo da ocupação Olga Benário, interceptada pela linha fronteiriça entre Belém e Ananindeua, evidenciou a complexidade envolvida no conflito de territorialidades quando a fronteira se define por meio de "linhas secas" apartadas dos processos socioespaciais.

De fato, na definição de fronteiras, é fundamental a participação dos moradores, dos gestores e legisladores, já que eles serão diretamente afetados com a proposta de readequação dos limites. Além disso, há que se considerar a natureza dos serviços públicos que atualmente são oferecidos na área de intervenção (escolas, postos de saúde, creches etc.), identificando se eles estão sob a gerência do município de Belém ou de Ananindeua. Não se pode perder de vista também a possibilidade de gestão integrada nas faixas limítrofes, estabelecendo parcerias/consórcios entre as prefeituras, como já é realizado em várias áreas metropolitanas no Brasil.

Todas essas questões constituem direcionamentos efetivos para futuras ações à luz das noções de território e de territorialidade. Ao levar em conta esses aspectos, a proposta que está sendo desenvolvida no âmbito da CODEM apresenta-se como um avanço no debate das questões de limites territoriais no Estado.

\section{Referências}

Belém. Câmara Municipal. (1994, 05 de janeiro). Lei no 7.682, de 05 de janeiro de 1994. Dispõe sobre a Regionalização Administrativa do Município de Belém, delimitando os respectivos espaços territoriais dos Distritos Administrativose dá outras providências. Belém: Câmara Municipal de Belém.

Belém. Câmara Municipal. (1996, 30 de julho). Lei nº 7.806, de 30 de julho de 1996. Delimita as áreas que compõem os bairros de Belém, revoga a lei no 7.245/84, e dá outras providências. Belém: Câmara Municipal de Belém

Belém. Prefeitura Municipal. (2014). Plano de trabalho para a redefinição dos limites territoriais de Belém. Belém: PMB.

Cataia, M. A. (2008). Fronteiras: territórios em conflito. In Anais do XIII Encontro Paranaense de Estudantes de Geografia (EPEG). Cascavel: Universidade Estadual do Oeste do Paraná. 
Ferrari, M. (2014). As noções de fronteira em geografia. Revista Perspectiva Geográfica Unioeste, 9(10), 1-25. Recuperado em 20 de fevereiro de 2016, de http://e-revista. unioeste.br/index.php/pgeografica/article/view/10161

Haesbaert, R. (2004). Dos múltiplos territórios à multiterritorialidade. In Anais do I Seminário Nacional sobre Múltiplas Territorialidades. Porto Alegre: Programa de Pósgraduação em Geografia da UFRGS. Recuperado em 10 de junho de 2014, de http://www.uff.br/observatoriojovem/ sites/default/files/documentos/CONFERENCE_Rogerio_ HAESBAERT.pdf

Instituto Brasileiro de Geografia e Estatística - IBGE. (2010). Censo demográfico de 2010. Rio de Janeiro: IBGE.

Instituto de Desenvolvimento Econômico, Ambiental e Social do Estado do Pará - IDESP. (2012). Projeto de revisão dos limites municipais. Pará: IDESP.

Pará. Assembleia Legislativa. (1948, 31 de dezembro). Lei $n^{\circ}$ 158, de 31 de dezembro de 1948. Define os limites municipais do Pará. Pará: Assembleia Legislativa.

Pará. Assembleia Legislativa. (1955, 11 de março). Lei $n^{o}$ 1.127, de 11 de março de 1955. Altera os limites municipais do Pará. Pará: Assembleia Legislativa.

Pará. Assembleia Legislativa. (1993, 15 de dezembro). Lei $n^{\circ}$ 5.778, de 15 de dezembro de 1993. Define os limites político-administrativos e territoriais entre os município de Belém e Ananindeua e dá outras providências. Pará: Assembleia Legislativa.

Raffestin, C. (1993). Por uma geografia do poder. São Paulo: Ática.

Ratzel, F. (1987 [1897]). La géographie politique. Paris: Fayard.

Ratzel, F. (1988 [1897]). Géographie politique. Genève: Editions Regionales Europeennes.

Sack, R. D. (1986). Human territoriality: its theory and history. Cambridge: Cambridge University Press.

Saquet, M. A. (2009). Por uma abordagem territorial. In M. A. Saquet, \& E. S. Sposito (Eds.), Território e Territorialidades: teorias, processos e conflitos (1. ed., pp. 73-94). São Paulo: Expressão Popular.

Souza, M. J. L. (2003). 0 território: sobre espaço e poder, autonomia e desenvolvimento. In I. E. Castro, \& R. L. Corrêa (Eds.), Geografia: conceitos e temas. Rio de Janeiro: Bertrand Brasil.

Recebido: Jan. 05, 2016

Aprovado: Mar. 22, 2016 